\title{
Escenarios de no-guerra: el papel de la música en la transformación de sociedades en conflicto**
}

\author{
Scenarios of no-war: the role of music in the \\ transformation of societies in conflict \\ Cenários de não-guerra: o papel da música \\ na transformação de sociedades em conflito
}

\footnotetext{
${ }^{*}$ Lic. en Edu. Artística. Magister en investigación Social. Miembro del Grupo de Investigación Literatura, Educación y Comunicación (LEC), Universidad Distrital Francisco José de Caldas. Su tesis de maestría fue opcionada por el jurado evaluador como laureada. Sus intereses y experiencia investigativa, se basan en los estudios afro, las ciencias cognitivas y la etnomusicología. Desarrolló trabajo de campo en San Basilio de Palenque, Cali y Bogotá. Su perspectiva investigativa transdisciplinar explora diversas posibilidades metodológicas como es el caso de las ciencias de la complejidad en sus múltiples variantes. Correo electrónico: lujanvillar@gmail.com

** Algunos aspectos teóricos y metodológicos de este artículo se originaron en el marco del proyecto de investigación Formas de producción sociocultural de la población afro juvenil en la ciudad de Cali: El caso del rap caleño en la década del noventa, apoyado económicamente por el Centro de Investigaciones y Desarrollo Científico de la Universidad Distrital Francisco José de Caldas, durante los años 2015 y 2016, con código 4-57-464-14, y fue asesorado por la Dra. Mirian Borja. Agradezco la revisión de tres pares anónimos y al editor encargado por las sugerencias realizadas a este escrito en sus diversos órdenes. Artículo de investigación recibido el 09/02/2016 y aceptado el 07/06/2016.
} 


\section{Cómo citar}

LUJÁN VILLAR, J. D. (2016). Escenarios de no-guerra: el papel de la música en la transformación de sociedades en conflicto. Revista CS, no. 19, pp. 167-199. Cali, Colombia: Facultad de Derecho y Ciencias Sociales, Universidad Icesi.

DOI: http://dx.doi.org/10.18046/recs.i19.2171 
Este artículo explora diferentes marcos de trabajo en la relación de la música, la guerra y la transformación de conflictos. Este estudio reflexiona sobre cómo la música puede aportar a las posibilidades de una paz duradera en sociedades situadas cerca al final de un conflicto histórico violento. Así mismo propone que los factores culturales, y especialmente la música, pueden a) identificar los conflictos sociales; b) pensar sus diversas soluciones en comunidad; y c) reflexionar a partir de algunos casos específicos las formas en las cuales la música posibilitó catalizar el dialogo y la transformación conflictual a través de la práctica y la reflexión musical.

PALABRAS CLAVE:

Música | Guerra | Etnomusicología | Post-conflicto | Imaginación narrativa

This article explores different frameworks between the relationship of music, war and conflict transformation. This study considers how music can contribute to the possibilities of a lasting peace in societies located near the end of a violent historical conflict. It also suggests that cultural factors, especially music, can; a) identify social conflicts; b) think its several solutions in the community; and c) consider, based on some specific cases, the way in which music allowed catalyzing dialogue and conflictual transformation through musical practice and reflection.

\section{KEYWORDS:}

Music | War | Ethnomusicology | Post-conflict | Narrative imagination 
Este artigo explora diferentes marcos de trabalho na relação da música, a guerra e a transformação de conflitos. Este estudo faz uma reflexão sobre como a música pode contribuir para possibilitar uma paz duradoura em sociedades situadas perto do final de um conflito histórico violento. Da mesma forma propõe que os fatores culturais, e especialmente a música, podem a) identificar os conflitos sociais; b) pensar suas diversas soluções em comunidade; e c) refletir a partir de alguns casos específicos as formas nas quais a música possibilitou catalisar o diálogo e a transformação conflitual através da prática e da reflexão musical.

\section{PALAVRAS CHAVES:}

Música | Guerra | Etnomusicologia | Pós-conflito | Imaginação narrativa 


\section{Introducción}

El trabajo que se presenta a continuación es resultado de una investigación sobre las formas culturales de producción de un colectivo musical étnico-afro a finales del siglo XX. Esta investigación surgió la necesidad de una reflexión teórica sobre los vínculos entre música, violencia, guerra y pacificación. A partir de los hallazgos de mi trabajo de campo durante varios años con los raperos de Cali (Luján, 2016a), tuve la necesidad de crear una propuesta que visibilizara la capacidad de la musicalidad humana a partir de experiencias prácticas en su mayoría internacionales sobre la música; el abordaje transdisciplinar que subyace a estos encuadres teóricos y la posibilidad de comprender cómo la música podría contribuir de modo potencial a catalizar el dialogo y la transformación conflictual de diversas maneras en Colombia. Algunas cuestiones correlacionadas se establecieron en diferentes grados como consecuencia de esta posición: ¿Cómo se pueden articular en el posconflicto colombiano posibilidades de diálogos socioculturales a partir de la música? ¿Qué relaciones existen entre la música y el conflicto en sociedades en situación de posguerra? ¿Cuáles fueron las experiencias que demuestran estas relaciones? ¿Qué posibilidades puede aportar la musicalidad a la resolución y transformación de conflictos?

El objetivo general de este artículo, es articular diversas posibilidades investigativas y de trabajo práctico estableciendo las relaciones entre música y conflicto en una sociedad en transición que cruza una etapa marcada por el diálogo, reconociendo algunas experiencias particulares sobre estos y otros tipos de nexos socioculturales. Para esta labor recurrí a una perspectiva etnomusicológica como posible aporte a un problema que no solo demostró ser propio de nuestro país, sino además de la contemporaneidad: la cuestión de las violencias de diversa índole, sus secuelas, y la resolución de los conflictos de manera pacífica. La profundización teórica que emprendí implicó una laboriosa y actualizada indagación del material bibliográfico consultado, el cual, como se puede inferir - por el tema tratado - fue difícil de adquirir, así como la comprensión del contexto subyacente a estas discusiones y sus debidos elementos de juicio, suscitando un aporte transdisciplinar basado en la etnomusicología, las ciencias cognitivas y los estudios afro.

Con la excepción de pocos trabajos sobre la guerra, la música y la resolución de conflictos (Bergh y Sloboda, 2010; O'Connell y Castelo-Branco, 2010; O'Connell, 2011; Urbain, 2008) el vacío existente sobre este tema es evidente (Robertson, 2010), la mayoría de los desarrollos relacionados con este campo surgen como estudios de caso separados de una articulación global que permita profundizar en diferentes puntos de vista teóricos, marcos de trabajo, encuadres metodológicos, y sobre todo en la capacidad de generar trabajos socioculturales poseedores de innovaciones en diversos ordenes bajo diferentes puntos de partida, tal como espero que pase a partir de la explicación a la que contribuyen los 
siguientes planteamientos. Al identificar este vacío se hace necesario preguntarse por la sensibilidad que produce la música y el lenguaje del diálogo como etapa preliminar a la superación de conflictos sociales, tal como la bibliografía disponible sobre este campo plantea desde comienzos de los años noventa, época en que la música y las artes se incluyen en la agenda de resolución de conflictos a nivel internacional (Bergh y Sloboda, 2010).

En septiembre de 2004 se celebró en Limerick (Irlanda), el International Council for Traditional Music (ICTM) un coloquio especial titulado "La discordia: Identificando conflictos en la música, resolviendo conflictos a través de la música" el cual reunió 26 expertos de diferentes partes del mundo. Este espacio académico tuvo como telón de fondo las interesantes experiencias irlandesas gestadas en contextos bélicos donde la música estableció un rol central en varios procesos de paz, especialmente en las negociaciones del histórico Acuerdo de Belfast (1998) (O’Connell y Castelo-Branco, 2010). Fue interesante en esta reunión que las discusiones giraron en torno a las perspectivas teoréticas y prácticas de los diversos roles musicales, a la par del reconocimiento de la educación musical y la musicoterapia. La identificación de conflictos, los múltiples posicionamientos musicales, políticos e ideológicos, y las formas interculturales de resolución de conflictos formaron el libro Music and Conflict, editado por John Morgan O'Connell y Salwa El-Shawan Castelo-Branco (2010), el cual es un referente central de consulta en esta área. Gómez (2011) recoge de manera eficiente los campos de acción del simposio desde una perspectiva etnomusicológica, que a su vez estructuran el libro; identificar el conflicto a través de la música, denunciar la censura y los usos violentos de la música, catalizar el dialogo a través de la práctica musical, formar ciudadanos críticos, archivar por la paz preservando la memoria y el patrimonio, analizar la repercusión de los discursos sobre la música y diseñar e implementar políticas culturales.

Algunos grupos de investigación enfocan las relaciones de la música y la guerra, por ejemplo desde la Segunda Guerra Mundial, como el caso del AMS Cold War and Music Study Group, donde musicólogos y etnomusicólogos se preguntan en retrospectiva por las particularidades musicales, artísticas y culturales que produjo la Guerra Fría en distintos órdenes de magnitud con una copiosa producción bibliográfica y una serie de 9 encuentros anuales llevados a cabo hasta la fecha ${ }^{1}$. Por otra parte, encontramos que algunos centros educativos se especializan en trabajar sobre los horrores de la guerra a partir del ejercicio musical, tal como The Pavarotti Music Centre (PMC) en Mostar, Bosnia-Herzegovina, en el mismo sitio donde quedaba la antigua escuela primaria. Este centro es auspiciado por la organización War Child, al lado de figuras de la talla de Luciano Pavaroti, Brian Eno y los miembros de U2. ${ }^{2}$ Su reconocimiento internacional es

\footnotetext{
1. Para consultar en detalle el acumulado bibliográficos del grupo: http://ams-net.org/cwmsg/

2. El plan de trabajo, los objetivos y los logros de este proyecto se pueden consultar en su portal web http://www. mcpavarotti.com/index_eng.htm
} 
significativo y es otro ejemplo notable sobre las posibilidades de cambio de la música en situaciones de post-guerra (se pueden examinar algunos detalles de este y otros centros para niños en la guerra en Haskell, 2015).

Músicos, practicantes y académicos, encuentran apoyo a la resolución de conflictos y su reducción en iniciativas de este tipo, a propósito de la fuente inagotable de evocaciones, reminiscencias, emociones y flujos cognitivos corpóreos que subyacen a la complejidad de la mente, los cambios de comportamiento y los estados anímicos a parir de los influjos musicales, como relata Oliver Sacks (2007), en las bellas historias clínicas en que reflexiona sobre la independencia de los circuitos neuronales asociados a los efectos biopsicológicos que la música produce en nuestro cerebro y conducta. Por estas razones las respuestas a situaciones difíciles a nivel social permiten que las músicas en sus inimaginables posibilidades de creación soporten salidas a tales condiciones. El siguiente documento está estructurado de la siguiente forma: primero se pregunta por el dialogo de la paz, introduciendo un acercamiento epistemológico práctico a la noción de conflicto; posteriormente explica de modo sucinto el abordaje metodológico aplicado, además de las consideraciones transdisciplinares en que se desenvolvió. Una tercera parte realiza el escrutinio de algunos casos prácticos sobre los usos de la música en procesos de desescalamiento/transformación de conflictos violentos, para proseguir con el análisis de la urgencia del cese al fuego en el marco de la reconciliación y el contexto social donde la música puede ejercer un papel primordial. Se propone a continuación la asertividad y la empatía dentro de la imaginación narrativa considerando algunas propuestas de mediación entre la música y la cooperación. Por último, se presentan algunos hallazgos de la corriente músicoterapéutica que aborda el problema de las secuelas de la guerra considerando la música como columna vertebral de sus planteamientos clínicos. El artículo se cierra con algunas conclusiones provisionales sobre los hallazgos encontrados en todas estas experiencias.

\section{Diálogos de paz y música: un marco teórico atravesado por la práctica}

Lejos de la dualidad paz y guerra, el conflicto parece estar inscrito en la naturaleza de la vida humana. Paz y guerra formarían parte de un continuum (O'Connell, 2011). Algunos teóricos del conflicto consideran que este definitivamente se debe enfrentar. Cascón (s.f: 6), por ejemplo, considera que la perspectiva de resolver problemas de tipo social respecto a las formas mediante las cuales los conflictos aparecen deben apuntar a: 1) descubrir la perspectiva positiva del conflicto en tanto posibilitador del dialogo (educativo) con fines de transformación social; 2) aprender a analizar los conflictos y a descubrir su complejidad, lo cual implicada reconocer las consecuencias entre las 
partes implicadas respecto a lo que se pierde y se gana con los conflictos; y 3) encontrar soluciones como paso ulterior de las discusiones que buscan la mediación. Su propuesta gira en torno a lo que se denominan acciones no violentas, en el marco de la mediación y la provención (concepto acuñado por J. Burton): la intervención en el conflicto antes de la crisis (Cascón, s.f: 6), lo cual sustenta a grandes rasgos su propuesta de prevenir conflictos y acciones violentas. Algunas de estas perspectivas nos acercan a los modos en que pueden existir acuerdos y arreglos de problemáticas violentas, desigualdad social y relaciones asimétricas del poder. Ahora bien, este enfoque nos deja ver que aunque el conflicto es inevitable, es susceptible de mediación, lo cual implica ir más allá de la lógica guerrerista tal como lo marcan el curso de los eventos históricos de la humanidad. Tal mediación necesita entonces de la capacidad de situar escenarios éticos de participación alternativa. Proponemos considerar la música como uno de ellos.

En su relación con el conflicto, O'Connell (2010) propone diferentes perspectivas del concepto, haciendo énfasis en la posibilidad de comprenderlo más allá de una perspectiva económica: implica reconocer sus razonamientos estratégicos en diferentes circunstancias y examinar múltiples posiciones entre los grupos en conflicto. Sobre la comprensión del conflicto en relación con la música O'Connell $(2010,2011)$ explica algunas ideas centrales de lo que puede significar el conflicto al interior de procesos musicales de diversa índole:

Cuando las prácticas musicales articulan las divisiones sociales, también pueden simular la cohesión social en la estructuración y textura del performance. Donde los performers trabajan a la vanguardia de la protesta, también pueden servir como intermediarios entre las entidades políticas opuestas (como embajadores) y entre los dominios espirituales divergentes (...) De manera significativa, el intercambio cultural de artistas musicales es a menudo uno de los primeros indicios de las intenciones pacíficas. Además, cuando los valores musicales se caracterizan por el prejuicio extremo, también pueden ser manipulados para fomentar la tolerancia, haciendo hincapié en la similitud de la práctica musical y mediante la aceptación de la diferencia en el gusto musical. De esta manera, la música ofrece la posibilidad de un ideal imaginario, una meta compartida que promueve la cooperación entre los grupos, mientras es respetuosa de las identidades culturales individuales (2O10:5).3.

Con base en lo anterior podemos deducir que los procesos musicales humanos implican reconocer diversos agenciamientos entre grupos de cara a la resolución de conflictos. Aspectos como la cohesión social, la intermediación entre grupos políticos opuestos, entre diferentes dominios espirituales y situaciones de extremo prejuicio, entre otros factores, promueven la cooperación entre grupos diversos en diferentes niveles: musicales, identitarios, económicos, étnicos (interculturales), al encontrar 
propósitos conjuntos cuya finalidad es realizar planteamientos para la resolución de diversas tensiones sociales. Como recuerda el mismo O'Connell (2010), en el caso de los Suyá de Brasil, analizado por Anthony Seeger (2010), y los albaneses en Kosovo, planteado por Jane Sugarman (2010), la música puede ser un arma poderosa para crear solidaridad intragrupal o también, paradójicamente, para estimular la agresión entre grupos diversos. O'Connell (2010) propone articular una etnomusicología del conflicto que estudie las complejas relaciones de la música en la guerra e, igualmente, para la paz, mediante la transformación de los conflictos como resultado final.

En el primer caso, el veterano etnomusicólogo Anthony Seeger pone de relieve "el papel de la música dentro del proceso negociador y en cómo la música junto a la danza ha ayudado a los Suyá a dar visibilidad a su causa" (Gómez, 2011). Ya que como el propio Seeger explica, los Suyá usan el canto con la finalidad de mantener su cultura (Seeger, 1987), "promoviendo una sensibilidad hacia los derechos de los indígenas que ha llegado a generar el apoyo de figuras internacionales como Sting, Bono o Grateful Dead" (Gómez, 2011). ${ }^{4}$ Otro ejemplo documentado en detalle es el trabajo adelantado por Jane Sugarman $(1999 ; 2010)$, quien analiza la manera en la cual el conflicto entre cristianos y musulmanes se alimenta de la música, en ocasiones de manera negativa, es decir, que su mensaje es utilizado unas veces para alimentar el odio y en otras para difundir una esperanza de resolución del conflicto. Sugarman (2010) analiza las maneras como la música podría mediar en el escalamiento y desescalamiento del conflicto en Kosovo. Su aporte nos invita reflexionar sobre las posibilidades de resolución de conflictos mediante la música; sobre todo hace énfasis en el poder de transformación de la música basándose en el consumo cultural de la audiencia albanesa.

Jeff Warren (2014) en la introducción de su libro Music and ethical responsibility, encuentra que existe un lugar ético de participación musical entre grupos heterogéneos (gentes diversas) como respuesta al conflicto, en este caso al ejercicio del poder. Su argumentación es pertinente en este espacio:

La negociación puede implicar una interacción intencional y un conflicto, pero en mi uso del término negociación también se lleva a cabo en la actividad cooperativa. Por ejemplo, el arrastre (o entrañamiento) - la capacidad de coordinar con otros ritmos - implica la negociación. Escucho otra persona canto y ajusto mi tiempo para coordinar. El resultado es un sonido que se genera a través de la negociación (2014: 6).

La idea central de esta argumentación es que la negociación, además de ser entre ritmos musicales y la capacidad creativa entre diferentes seres, también posee un componente contextual, interrelacional, basado en la experiencia de hacer y escuchar

\footnotetext{
4. Este aspecto fue analizado y fuertemente señalado por Carvalho (2004) como fetichismo cultural.

5. Traducción propia.
} 
música. En este punto vemos la necesidad de articular la propuesta de comprender la correspondencia entre música y posibles escenarios de no-guerra. La idea de Warren (2014) va inclusive más allá y encuentra cómo en la práctica del músico-interprete (performer) existen responsabilidades con otros músicos interpretes (performers) y además, con los escuchas quienes están por fuera del acto performático pero se encuentran en el interior del mensaje (Warren, 2014: 9). Es importante recordar que Warren sugiere que la responsabilidad ética de la música surge en el encuentro con el 'Otro' cara-a-cara, es decir, según la concepción donde ese otro no es un ser distante, y por el contrario el encuentro cara-a-cara sitúa la percepción que ambos tienen de las situaciones y relaciones concebidas. En nuestra concepción encontramos que los significados de la música al igual que los de la guerra resultan cuando son experimentados. Tales significados se descubren en su totalidad cuando las situaciones permiten que la percepción de aquello que brinda la posibilidad de expresión o de sentir dolor sean acciones corporizadas. Mediante las ocasiones culturales donde ambas expresiones - la música y la guerra- entran en juego (cada una a su modo) y pasan a ser parte de la corporalidad de sus actores. Debe existir una oportunidad ética, una oportunidad del cambio, del diálogo, de la búsqueda de una paz, ya que tanto la música como la guerra tienen un fin. Y aunque la música no es correctivo de la guerra por excelencia, los escenarios musicales pueden ser puntos de cimentación de lugares de no-guerra como lugares de consideración de las necesidades del 'Otro'.

\section{Metodología}

El abordaje metodológico de este estudio comprende dos fases. La primera se basa en una perspectiva comparativa que se sitúa en la identificación de casos relacionados entre la música y la guerra. Para esto se recurrió a un diseño bibliográfico al cual subyacen los datos recogidos en los planteamientos teóricos, epistemológicos y las aplicaciones de técnicas investigativas y de trabajo clínico, para explorar una posibilidad demostrativa de la capacidad de la música en la vida humana, a partir de análisis de casos donde la guerra y violencia marcaron los contextos sociales abordados. Es necesario reconocer que estas comparaciones obedecen al establecimiento de contextos paralelos al colombiano (tal como se intentó articular en el Grafico 1), sobre investigaciones que emprendieron procesos de resolución/transformación de conflictos a través de la música. Esta configuración metodológica se puede denominar como estudio de carácter exploratorio con una fuerte carga referencial a un campo que demostró aportar a la transformación de la vida real. Para elaborar una comparación es necesario establecer los criterios mejor adecuados para la categorización, por esta razón mi indagación mantuvo al mismo nivel los diversos tipos de músicas como centrales en los ejemplos presentados, invitando 
a concebir la música como un fenómeno sonoro universal en el género homo, y a las respuestas a sus diversas materializaciones como productos establecidos y relacionados creativamente particulares de cada contexto sociocultural.

La segunda fase de este estudio comprendió la recolección de información de tipo teórico y técnico y de aplicación en los niveles que delimitan los alcances de estas investigaciones, abriendo el panorama a algunas posibilidades procedimentales de aplicación en el trabajo con poblaciones a partir de diversas disciplinas, con la finalidad de generar impacto social. Para esto fueron considerados casos que incluyeran perspectivas étnicas e interétnicas, lo cual conecta con la articulación metodológica propuesta en la investigación Formas de producción sociocultural de la población afrojuvenil en la ciudad de Cali: El caso del rap caleño en la década del noventa, que elaboré durante varios años. En esta investigación adelanté trabajo de campo en Cali y Bogotá, aplicando una etnografía en perspectiva analítica de la música rap, una serie de análisis performáticos a nivel etnomusicológico y una indagación y procesamiento de datos sociológicos y antropológicos. Como estrategia complementaria recurrí al análisis de los estudios de la paz, los estudios de resolución de conflictos y a las estrategias de la psicología cognitiva aplicada a la música y las artes.

La apuesta metodológica que subyace a esta propuesta investigativa, radica en la posibilidad de establecer un marco de trabajo basado en el intercambio transdisciplinar. Desde este punto de vista, esta consideración conjunta intenta dar luz sobre la emergencia de un repertorio conceptual asociado al problema de la música bajo diferentes rubros metodológicos. Esta configuración permite una implementación que va de lo teórico a lo práctico. Sin embargo, es imprescindible manifestar que esta táctica procura vislumbrar una exploración adecuada de un trabajo específico, ya que al momento de abordar el trabajo con comunidades involucrando la música como medio adecuado, los conocimientos profesionales deben ser de diversa índole: musicológicos, pedagógicos, clínicos, socioculturales y además debe soportar una epistemología fundamentada en la posibilidad de generar formas innovadoras de articulación dialógica a nivel social.

\section{Escenarios de no-guerra: el uso de la música como mediadora en contextos de guerra}

Existen escenarios de guerra donde la música ejerce una fuerte influencia en los estados emocionales de quienes la escuchan. Jonathan Pieslak (2009) en su libro Sound Targets: American Soldiers and Music in the Iraq War, identifica cómo los soldados norteamericanos de la guerra de Irak usan de diferentes maneras la música: descubrió que efectivamente la música juega un papel importante en el reclutamiento militar: "Music played an important role in these efforts to attract soldiers and was utilized most prominently 
in television advertisements and propaganda videos" (18), recordando que no solo en Irak, sino además en Corea y Vietnam también se usó propaganda de reclutamiento, por lo general en canales de audiencias jóvenes entre los 17 y 25 años de edad. Por otra parte, su trabajo pudo focalizar cómo algunas grabaciones musicales y presentaciones en vivo de diversos artistas y épocas fueron usadas como inspiración para el combate, ya que desde la Segunda Guerra Mundial los campamentos militares establecieron emisoras de radio, siendo estos espacios cercanos a la vida del soldado y en ocasiones su primera fuente musical (2009: 48).

En sus entrevistas con soldados hombres y mujeres, Pieslak (2009) evidenció que el rap y la música metal son preferidos por los combatientes norteamericanos en el momento del pre-combate y durante este. No obstante, debemos aclarar que tanto el rap como el metal son tendencias musicales populares y parte del repertorio y experiencias musicales de diferentes grupos sociales en el planeta. Es decir, no existe un metal o rap genérico o unidireccional. Si existen juicios de valor o prejuicios musicales no será precisamente señalando a determinadas tendencias liricas la manera más adecuada para que las cosas cambien de rumbo. Es mejor comprender estos fenómenos como potentes conductores de comportamientos, esto sugiere considerar la música en íntima relación con situaciones particulares en los procesos cognitivos y emocionales en el accionar de las personas. Después de sus análisis, la argumentación que articula Pieslak (2009) respecto a los usos de la música en tanto inspiración para la transformación humana es muy interesante:

La idea de la influencia transformadora de la música o las creencias religiosas entre los combatientes en la guerra de Irak puede ser paradójicamente alentadora. La auto-transformación de los combatientes sugiere que ambas partes del conflicto deben tomar medidas, de alguna manera, para alterar su estado psicológico de tal manera que son capaces de matar. Muchos soldados vieron la condición de la guerra como antinatural. De hecho, esto apunta a la idea de que las personas de las sociedades y creencias radicalmente diferentes, al igual que los soldados estadounidenses e insurgentes musulmanes, a menudo toman medidas para la auto-transformación con el fin de ser capaz de cometer actos de extrema violencia (Pieslak, 2099: 167). ${ }^{6}$

La capacidad de influencia musical sobre los estados anímicos de los soldados en Irak es un hallazgo interesante de Pieslak (2009), además identifica aquellos usos de los repertorios musicales de los solados, fundamentales en sus rituales antes de salir al campo y también en momentos de paz. El rap y el metal entonces juegan un rol importante en el contexto de la guerra de Irak, inclusive un grupo de soldados bajo el nombre de 4 th 25 produjo un disco titulado Live from Iraq, grabado en Bagdad en plena 
guerra, con un estilo rapero (mezcla de gangsta rap, integridad y responsabilidad). En este disco los soldados revelan su propia experiencia, al igual que los soldados Nick Brown y David Schultz, quienes grabaron Iraq Unplugged (2005), canciones de su propia autoría acompañados de sus guitarras, o William Thompson quien grabó Baghdad Music Journal, una mezcla de samples propios del entorno de la guerra de Irak y sonidos electrónicos bajo un estilo jazz. Las nuevas tecnologías posibilitaron que los combatientes pudieran expresar su propia experiencia de la vida, la muerte y la esperanza en medio de la misma guerra. Según lo anterior nos preguntamos: ¿Puede la música mediar en contextos de conflicto?, ¿los ejemplos anteriores son casos aislados dentro de los capítulos planetarios de las guerras en el siglo XX y XXI?

Este caso nos permite evidenciar cómo la memoria en relación con la música puede llevar a diferentes planos de la experiencia humana, la idea etnomusicológica de resolución de conflictos puede acercarnos a las maneras mediante las cuales una etnografía de la memoria en situaciones de violencia aguda ayude a buscar mecanismos de diálogo, acciones cooperativas y finalmente la transformación de situaciones violentas en no violentas. Es decir, así como la misma etnomusicología contemporánea condena el uso de la música como tortura (Society for Ethnomusicology SEM, 2007), ella también puede influenciar la trasformación positiva en el ser humano. Esta paradoja nos permite evidenciar que la capacidad musical puede ideologizar el comportamiento que rigen las fuerzas sociales sobre el sujeto, pero al mismo tiempo puede liberarlo de su propio orden social regido por la realidad ordinaria.

Más que una ilusión, el momento musical puede ser la esperanza que la asimetría del poder niega al ciudadano(a) de a pie, dejemos que Žižek (2006) nos dé un ejemplo de la ironía del uso musical en la cultura:

\footnotetext{
Durante el rodaje en las afueras de Madrid de la película de David Lean Doctor Zhivago, una multitud de figurantes españoles tuvo que cantar la "Internacional" en una escena en que aparecía una manifestación masiva. El equipo de rodaje quedó asombrado al descubrir que todos conocían la canción y que la cantaban con tanto entusiasmo que dio lugar a la intervención de la policía franquista, que pensaba encontrarse frente a una manifestación política real. Y, lo que es más, cuando ya había anochecido (la escena tenía que desarrollarse en la oscuridad), la gente que vivía en las casas de los alrededores oyó los ecos de la canción, empezó a abrir botellas y a bailar en la calle, suponiendo equivocadamente que Franco había muerto y que los socialistas habían tomado el poder (16).
}

Superando la relación entre la comunicación musical y la música en la comunicación, vemos que existe un nexo entre la posibilidad de resolución de conflictos en el marco de la libertad de los pueblos, ya que su derecho a la vida encuentra en la música un nicho de esperanza. Refugio en el cual, a través de la acción la esperanza se torna 'real', convirtiéndose en definitiva para la orientación agencial de las comunidades en 
situaciones de conflicto y violencia extrema, dictaduras, guerras o relaciones asimétricas del uso del poder.

\section{Algunos casos sobre los usos de la música en procesos de des-escalamiento/transformación de conflictos violentos}

Lotta Harbom y Peter Wallensteen (2007) encontraron, desde el final de la Segunda Guerra Mundial, un total de 232 conflictos armados activos en 148 locaciones en el mundo. En su tipología descubren que tales locaciones pueden ser intraestatales e interestatales, las primeras ocurren dentro de un país y las segundas entre dos o más países. Ahora bien, un conflicto de tipo intraestatal (conflicto interno armado) puede ser catalogado como internacional (conflicto interno armado internacionalizado) cuando un estado externo interviene como apoyo a otro estado (Harbom y Wallensteen, 2007: 626). Esta tipología de los conflictos violentos deja ver que también la paz puede ser internacionalizada, ya que de 1946 a 2006 Colombia - como escriben los autoresademás de poseer el único conflicto de su naturaleza, lleva 51 años ininterrumpidos:

Out of the 32 armed conflicts in 2006, 11 had been active for more than ten consecutive years. Many of the remaining 21 had been going on for over ten years, then experiencing a lull for a year or two, only to restart again. Thus, a group of highly protracted conflicts makes up the core of present global conflict. The one with the longest uninterrupted activity is the 41-yearold conflict fought over government power in Colombia. International efforts at conflict resolution now encounter protracted conflicts that are more difficult to resolve, as they have been entrenched in the social fabric and the parties have learned how to block peace efforts (Harbom y Wallensteen, 2007: 626).?

Su análisis permite comprender la dificultad del conflicto colombiano y su particularidad a nivel internacional. Según el Uppsala Conflict Data Program (UCDP), el conflicto armado como categoría de análisis se define como "una incompatibilidad impugnada, que se refiere a gobierno o territorio o ambos, cuando el uso de la fuerza armada entre dos partes da como resultado al menos 25 muertes relacionadas con los combates en un año" (Harbom y Wallensteen, 2007: 632). ${ }^{8}$ No obstante, aún en una situación tan difícil la música pervive. El estudio de la música en sociedades en conflicto y post-conflicto nos puede llevar al análisis y adecuación del reconocimiento de la paz, la resolución de diversas problemáticas y la cooperación entre grupos humanos. En este sentido la

7. Traducción propia.

8. Traducción propia. 
música puede entenderse como un proyecto humanitario, una posibilidad de definir la paz en épocas de transición social, una oportunidad de cambio.

$\mathrm{Al}$ abordar el problema de la música como mediación en contextos de guerra emerge este cuestionamiento: ¿Cómo se pueden aplicar encuentros interculturales en sociedades post-guerra con ánimo de resolución de conflictos basándose en la música? Para responder esta pregunta nuestra investigación consideró una extensa y exhaustiva consulta bibliográfica que pudiera evidenciar investigaciones con grupos humanos en el sentido de trabajar la música en sí misma y con el pretexto de generar cambios sociales en diversos niveles. La investigación de Craig Robertson (2010), estudio de caso llevado a cabo en Bosnia, encontró un coro interreligioso situado en Sarajevo (Bosnia-Herzegovina) dedicado al canto coral litúrgico de las tradiciones católica, ortodoxa, musulmana y con adición de música judía. En su survey desde la sociología de la música ubica cómo el sentido de la identidad musical es atravesado por una propuesta intercultural que abarca diferentes religiones. En sus conciertos el coro canta dos canciones de cada fe, y tiene una importante proyección internacional presentándose para la UNESCO en París en 2003 y para World Council of Churches Inter-religious Conference en Génova en 2005, pero por lo general sus performances se realizan en áreas de guerra (Robertson, 2010). Su puesta en escena se basa en una clásica dirección orquestal y se presenta al estilo de ópera clásica dinamizando en ocasiones un repertorio igualmente clásico.

Robertson (2010), explica que la importancia de este coro reside en la forma en la que en un país con un desempleo del $45 \%$, y con una tendencia nacional que duda de la paz y que difícilmente la concibe como cese temporal al fuego, el coro propone una actividad cultural tolerante y propia de la sociedad de Sarajevo pre-guerra (Robertson, 2010), la cual - según sus habitantes - cambió con los flujos de inmigrantes (por lo general húngaros, judíos y musulmanes) debido a algunas visiones radicales nacionalistas y religiosas. Aunque existen diferentes identidades religiosas en Bosnia: bosnio serbio (ortodoxo), bosnio croata (católico) y bosniak (musulmán). En sus hallazgos el investigador encontró cómo la noción de 'lo normal' dentro del coro aplica para las maneras de respeto y tolerancia interreligiosa de preguerra en la sociedad de Sarajevo: "si se les pregunta, la mayoría (miembros) cree que este acto de recordar a través de la música ayudará a las comunidades a volver a aprender cómo cooperar y 'desaprender' sus tendencias nacionalistas" (Robertson, 2010). El problema evidenciado por el etnomusicólogo es la forma en la cual se puede resolver un problema de modo colaborativo. En este caso es el fortalecimiento social a partir de las diferencias interétnicas y los nacionalismos implicados en un escenario posguerra. Consideremos las formas en las cuales un grupo musical en una sociedad como la bosnia intenta de manera creativa re-aprender, cooperar y también desaprender las tendencias nacionalistas que subyacen a las formaciones y experiencias político-culturales de cada grupo. Podríamos realizar un emplazamiento de esta perspectiva situando problemáticas de orden ideológico, 
como las tendencias políticas, los problemas derivados de la memoria social y toda la complejidad que se encuentra en las violencias contemporáneas. Dado que el conflicto violento evolucionó, también lo deben hacer las salidas posibles a esta situación.

El otro caso es bastante conocido por todos nosotros, pero debe ser reflexionado según la perspectiva de transformación de conflictos. El 22 de abril de 1978 en Jamaica el cantante de reggae Bob Marley - en su performance del concierto por la paz realizado en Kingston (Jamaica) - logró reconciliar y entablar una tregua nacional entre los líderes del Partido Laborista de Jamaica (JLP), Edward Seaga, y del Partido Nacional del Pueblo (PNP), Michael Manley. El título del monumental evento musical fue decisivo One Love Peace Concert, y fue además el lanzamiento oficial de la música reggae, un multitudinario llamado a la paz por parte de sus 32.000 asistentes para conmemorar el duodécimo aniversario de la visita a Jamaica del emperador etíope Haile Selassie (Ras Tafari).

La fuerza de Marley al realizar esta hazaña casi le cuesta la vida dos años antes, cuando fue baleado en 1976 durante la preparación del concierto Smile Jamaica, organizado por la Sección Cultural de la Oficina del Primer Ministro (Michael Manley), el cual se realizaría el 5 de diciembre junto a The Wailers y las I Thress. En realidad el reggae fue usado con fines políticos en las elecciones de 1972 y mucho más en las de 1976 por parte de las campañas del PNP y el JLP. Ahora bien, el One Love Peace Concert tuvo como primer objetivo recaudar fondos para los aspectos sanitarios del guetto del occidente de Kingstone (Trenchtown), y como segundo retornar a Jamaica a Marley quien se exiliaría en Inglaterra después del atentado en contra de su vida dos años antes. El clímax del evento se percibió cuando al final de la canción Jammin invitó al escenario a Manley y Seaga y unió sus manos como gesto de humanidad y unión del pueblo jamaiquino, marcando la tregua entre ambos partidos. En el contexto de la Jamaica de los años 70 se debe reconocer la complicada crisis que atravesaba el país en materia económica, debido según muchos a la influencia de Estados Unidos y la intervención de la CIA en la vida social de la isla (Giovannetti, 2001).

Consideramos que se muestra de esta manera cómo un conflicto inicialmente detectado por la música puede tener incidencia directa en su resolución. Es preciso reconocer que en el concierto One Love Peace Concert el artista central era Marley y su banda, pero en el escenario del National Stadium también actuaron los artistas de reggae más importantes de la isla en su momento: Althea and Donna, Dennis Brown, Culture, Dillinger, The Meditations, Jacob Miller and Inner Circle, Peter Tosh, Bob Marley and The Wailers y Young Youth entre otros. Esto significa que la fuerza de la consigna rastafari era imposible de ignorar en términos políticos y, más aún, era trascendental en la transformación de la isla. Este caso deja claro que incorporar el conflicto y promulgar un compromiso de cambio es posible mediante el poder musical para subvertir la resistencia retórica de algunos actores al margen del objetivo principal en contextos de alta violencia, y crear entornos de no-guerra. En este caso, 
el modo de ser rastafari y pertenecer a una clase oprimida históricamente fue utilizado como elemento de una comunicación pacificadora y rebelde ante la injusticia del aniquilamiento sistemático étnico-racial afro, manifestado en el caso de Peter Tosh y su régimen discursivo durante el concierto.

Estos casos nos permiten comprender de diversos modos de qué manera la música puede mediar en la resolución de conflictos y cómo algunos etnomusicólogos plantean su transformación. La música puede dividirnos o unir nuestros esfuerzos mediante el trabajo cooperativo. Lo que se escribió recientemente sobre casos en que la música media nos remite a ejemplos concretos donde la gente utilizando la música y su elaboración, planteamientos espirituales, ejercicios de ciudadanía diferenciada y étnico-racial o centros de desarrollo cultural puede mantener indicadores de calidad de vida que contribuyen claramente al mejoramiento de sus condiciones debido a la transformación de conflictos sociales de diversa índole. Estos estudios demostraron que al contrario de alcanzar una paz idealmente perfecta, se pueden crear escenarios de no-guerra y contribuir a la invención de altos niveles de armonización entre formas de ser divergentes. Recientemente Erica Haskell (2015), en su trabajo The Role of Applied Ethnomusicology in Post-Conflict and Post-Catastrophe Communities analiza diversos casos en África, Asia y Europa del Este donde la música, a través de centros de desarrollo cultural, ONG, programas y el activismo etnomusicológico son prueba de la importancia de entablar posibilidades de lo musical en contextos post-guerra y post-catástrofe. Su trabajo propiamente se desarrolló en Bosnia y apunta a la consolidación de la etnomusicología aplicada, una forma de desarrollo musical en la cultura. En su investigación concluye:

Como consecuencia de ambos conflictos y desastres naturales, los cooperantes culturales tienen recursos muy necesarios, y a menudo son recibidos con los brazos abiertos en los países receptores. En otros casos, los proyectos musicales y culturales se desarrollan y ejecutan por actores con relativamente poca experiencia en cuestiones culturales. En situaciones en las que las ONG y las instituciones están tratando de llenar las necesidades básicas de las comunidades a las que sirven, los productos culturales pueden tener un valor auxiliar: dibujando una multitud, incluyendo a las personas, la recaudación de dinero, la venta de un producto, y explicando nuevos conceptos. Los músicos también son utilizados por los políticos y las comunidades por igual para simbolizar cómo los ciudadanos inocentes han sido afectados por desastres naturales o provocados por el hombre (Haskell, 2015: 476).

De manera precisa, Haskell (2015) puntualiza sobre la importancia de diferenciar las catástrofes y los post-conflictos según son provocados por el hombre o por la naturaleza. Aunque la producción cultural para muchos no es considerada como una necesidad prioritaria, algunas investigaciones nos dicen que existen imaginarios, ideologías y heroísmos que afectan las relaciones interétnicas; por supuesto esto hace parte de un proceso que es producto de la cultura y sus entramados (O'Connell, 2011: 
116; Robertson, 2010; Sugarman, 1999, 2010). La música, como sabemos, cuestiona estos supuestos y puede ayudar a discutir las salidas de estas situaciones conflictivas reevaluando su impacto. La transformación de conflictos mediante la música es una posibilidad que contempla un panorama aún más grande: la necesidad de suspender las acciones violentas específicas contra la vida.

\begin{tabular}{l|l} 
TABLA 1 & Investigaciones sobre procesos de resolución/transformación
\end{tabular} de conflictos a través de la música

\begin{tabular}{|c|c|c|c|}
\hline Aspecto de indagación & Conflicto/agentes & Locación & Autor/es \\
\hline Soporte cultural amenazado & Etnicidad y sociedad & Brasil & $\begin{array}{l}\text { (Seeger, } 1987 \\
2010)\end{array}$ \\
\hline $\begin{array}{l}\text { Resolución de conflictos } \\
\text { violentos }\end{array}$ & $\begin{array}{l}\text { Identidades } \\
\text { étnicoreligiosas }\end{array}$ & $\begin{array}{c}\text { Bosnia- } \\
\text { Herzegovina }\end{array}$ & (Robertson, 2010) \\
\hline $\begin{array}{l}\text { Identificación de los nexos } \\
\text { entre procesos artísticos y } \\
\text { la resolución de conflictos } \\
\text { comunitarios }\end{array}$ & $\begin{array}{l}\text { Grupos identitarios en } \\
\text { conflicto }\end{array}$ & $\begin{array}{c}\text { Bosnia- } \\
\text { Herzegovina }\end{array}$ & (Zelizer, 2003). \\
\hline Conflicto y violencia & Grupos étnicos urbanos & Brasil & (Araújo, 2006) \\
\hline Hostigamiento y tensiones & $\begin{array}{l}\text { Sociedades } \\
\text { multiculturales/ } \\
\text { interétnicas }\end{array}$ & Noruega & (Skyllstad, 1997). \\
\hline $\begin{array}{l}\text { Canciones, mitos ideológicos y } \\
\text { guerra }\end{array}$ & $\begin{array}{l}\text { Identidades } \\
\text { étnicoreligiosas }\end{array}$ & $\begin{array}{l}\text { Kosovo (sureste de } \\
\text { Europa) }\end{array}$ & $\begin{array}{l}\text { (Sugarman, 2009, } \\
2010)\end{array}$ \\
\hline Música y conflicto & Etnicidad y sociedad & & (Reyes, 2006) \\
\hline $\begin{array}{l}\text { Música y conflicto- relaciones de } \\
\text { reconstrucción étnica }\end{array}$ & Refugiados vietnamitas & $\begin{array}{l}\text { Vietnam, Estados } \\
\text { Unidos }\end{array}$ & (Reyes, 1999) \\
\hline Música, conflicto y guerra & $\begin{array}{l}\text { Grupos étnicos urbanos, } \\
\text { Grupos identitarios en } \\
\text { conflicto }\end{array}$ & $\begin{array}{l}\text { Kosovo, Bosnia- } \\
\text { Herzegovina, } \\
\text { Brasil, Estados } \\
\text { Unidos, Azerbaijan, } \\
\text { Irlanda del } \\
\text { Norte, Indonesia } \\
\text { Alemania, }\end{array}$ & $\begin{array}{l}\text { (O'Connell y } \\
\text { Castelo-Branco, } \\
\text { 2010) }\end{array}$ \\
\hline $\begin{array}{l}\text { Música, conflicto, guerra y } \\
\text { catástrofes }\end{array}$ & $\begin{array}{l}\text { Sociedades en post- } \\
\text { conflicto y post- } \\
\text { catástrofes }\end{array}$ & $\begin{array}{l}\text { Bosnia- } \\
\text { Herzegovina, } \\
\text { Estados Unidos, } \\
\text { Haití }\end{array}$ & (Haskell, 2015). \\
\hline Soldados en guerra & $\begin{array}{l}\text { Relaciones } \\
\text { interculturales, } \\
\text { conflicto bélico }\end{array}$ & $\begin{array}{l}\text { Irak, Estados } \\
\text { Unidos }\end{array}$ & (Pieslak, 2009) \\
\hline Música en el mundo Post-9/11 & $\begin{array}{l}\text { Sociedades } \\
\text { contemporáneas y } \\
\text { sociedades en post- } \\
\text { conflicto, }\end{array}$ & $\begin{array}{l}\text { Estados Unidos, } \\
\text { Canadá, Irak, } \\
\text { Marruecos, } \\
\text { Senegal, Medio } \\
\text { Este, México }\end{array}$ & $\begin{array}{l}\text { (Ritter y Daughtry, } \\
\text { 2007) }\end{array}$ \\
\hline
\end{tabular}




\begin{tabular}{|c|c|c|c|}
\hline Aspecto de indagación & Conflicto/agentes & Locación & Autor/es \\
\hline Música y sostenibilidad & $\begin{array}{l}\text { Desplazamiento } \\
\text { internacional }\end{array}$ & Plano internacional & (Bergh, 2008) \\
\hline Artes y resolución de conflictos & $\begin{array}{l}\text { Grupos sociales en } \\
\text { conflicto }\end{array}$ & Plano internacional & (Liebmann, 1996) \\
\hline Música, política y guerra & $\begin{array}{l}\text { Grupos étnicos y } \\
\text { sociedades en post- } \\
\text { conflicto }\end{array}$ & Croacia & (Pettan, (1998) \\
\hline $\begin{array}{l}\text { Música y transformación de } \\
\text { conflictos, geopolítica de la } \\
\text { música }\end{array}$ & $\begin{array}{l}\text { Estudios sobre la paz, } \\
\text { las conductas musicales } \\
\text { y la vulnerabilidad } \\
\text { colectiva }\end{array}$ & $\begin{array}{l}\text { Estados Unidos, } \\
\text { Medio Este }\end{array}$ & (Urbain, 2008) \\
\hline $\begin{array}{l}\text { Procesos de mediatización y } \\
\text { elaboración musical }\end{array}$ & $\begin{array}{l}\text { Sociedades post- } \\
\text { conflicto, desregulación }\end{array}$ & $\begin{array}{c}\text { Europa post- } \\
\text { comunista, } \\
\text { Bulgaria, Rumania }\end{array}$ & (Kurkela, 1995) \\
\hline $\begin{array}{l}\text { Análisis de un corpus de } \\
\text { canciones escritas }\end{array}$ & Víctimas del conflicto & Colombia & (Pinto, 2014) \\
\hline $\begin{array}{l}\text { Relaciones entre música y } \\
\text { guerra y transformación del } \\
\text { conflicto }\end{array}$ & $\begin{array}{l}\text { Grupos sociales en } \\
\text { conflicto y sociedades } \\
\text { en guerra y post-guerra }\end{array}$ & Plano internacional & (O'connell, 2O11) \\
\hline
\end{tabular}

\section{La urgencia del cese al fuego'}

El cese al fuego es hoy más necesario que nunca. Algunas versiones sobre la economía del país así lo dejan ver, ya que los estimados económicos prevén un incremento considerable respecto al objetivo de lograr una paz estable con justicia social. En esta etapa de negociaciones y procesos de resolución del conflicto armado entre las partes vinculadas en Colombia, quedan pocas dudas respecto a los beneficios económicos que traería el cese al fuego definitivo: "Con conflicto armado, el PIB departamental se duplica cada 18,5 años, y sin conflicto armado, se duplicaría en 8,5 años. Colombia ganaría una década de crecimiento" (Arias et al., 2014).

Según un informe de las Naciones Unidas sobre Desarrollo Humano, como recuerda Stiglitz (2012): "El único país donde la desigualdad tenía un efecto negativo mayor era Colombia”, lo cual sugiere aún más la necesidad de pensar el post-conflicto colombiano en términos de inclusión y desarrollo humano (Arias et al., 2014) lo explican de manera clara en un interesante estudio sobre los beneficios multidimensionales de la no-guerra en Colombia: "El conflicto armado genera altos costos para la sociedad a través de una reducción en la producción agrícola y manufacturera, una caída en la inversión extranjera y un deterioro de la salud física y mental de la población” (Arias et al., 2014). 
Además de semejantes argumentos, urge el cese al fuego si tenemos en cuenta el balance que realiza Piketty (2014), sobre la particularidad del caso colombiano (según él muy parecido a China) respecto a la desigualdad en los ingresos - si consideramos a Colombia como un país emergente-, solamente está por debajo de países altamente desiguales como los Estados Unidos:

Colombia parece ser uno de los países más desigualitarios registrados en la World Top Incomes Database: la participación del percentil superior se situaba en torno a $20 \%$ del ingreso nacional durante los años 1990-2010, sin una tendencia clara (...). Se trata de un nivel de desigualdad aún más elevado que el alcanzado por los Estados Unidos en 20002010, por lo menos si se excluyen las plusvalías: al incluirlas, los Estados Unidos superaron ligeramente a Colombia a lo largo de los últimos diez años (Piketty, 2014).

Es pertinente recordar que la inequidad y la desigualdad son conceptos diferentes aunque se los tienda a relacionar como símiles, el primero incluye un componente calificativo, es decir un componente ético, y el segundo atiende a una idea que proviene de una distribución de tipo estadístico. Puntualmente, al hablar de inequidad nos referimos a aspectos que subrayan la barbarie de la desigualdad contemporánea. Así, la inequidad en tanto juicio ético se puede entender como el resultado de la desigualdad, las inequidades se escapan de la medida justa y se las comprende como injusticas, por ejemplo, cuando un grupo social posee desiguales oportunidades para acceder a los servicios de salud o de educación. El trabajo reciente de Camacho y Rodríguez (2013), sobre la influencia del conflicto armado en nuestro país demuestra cómo afecta la guerra en la actividad económica, de acuerdo a la salida de diferentes plantas de trabajo del país, lo cual disminuye a su vez oportunidades de trabajo y aumenta la salida de capital. Escriben las autoras:

Estos primeros resultados contribuyen a la comprensión de los posibles canales directos a través de los cuales el conflicto influencia la actividad económica. La carga que la violencia impone sobre la economía, aumenta la salida de la planta y podría ser medida por el costo de oportunidad del capital que sale del sector manufacturero (Camacho y Rodríguez, 2013: 110).

Como vemos, algunas perspectivas económicas plantean la necesidad de acabar con el largo conflicto armado que vive Colombia, el más antiguo en su especie en Latinoamérica y uno de los más antiguos a nivel mundial en el siglo XX (Harbom y Wallensteen, 2007). Es importante recordar que el post-conflicto es una fase de transición dentro de los cambios propuestos respecto a reformas, cambios en diferentes niveles (constitucionales, institucionales), reparaciones en el plano económico y por supuesto en aspectos de la vida sociocultural (memoria, territorio, religiosidad) de las 
víctimas y la sociedad en general. Sobre este último punto, encontramos que la música se conecta de manera directa en una posibilidad que involucra los diversos estamentos de la sociedad en una sociedad post-conflicto, ello es la reconciliación (Jeong, 2010; Pinto, 2014; Haskell, 2015: 463).

\section{Reconciliación y contexto social}

En la búsqueda de una serie de pasos hacia la superación de la enemistad, la música parece haber funcionado de manera acertada. La palabra reconciliación articula una mediación en diferentes niveles, no obstante uno de esos niveles es el emocional, y la emocionalidad de una persona es susceptible de encontrar en la música un sin número de posibilidades expresivas en diferentes contextos socioculturales y especificidades cognitivas. No es este el sitio para plantear una visión utilitarista de la música y sus diversos procesos de congregación social (trabajo cooperativo, experimentaciones interculturales, creación colectiva entre otras), por el contrario nuestra perspectiva subraya aquellos ejemplos y casos donde los usos musicales y artísticos tuvieron resultados positivos respecto a la restauración de relaciones tolerantes y en algunos casos a nivel de alteridad.

Diríamos que el poder de la música también puede cambiarnos, pero sobre todo, reconciliarnos con el otro. Algunos programas adelantados sobre el uso de música en contextos altamente multiculturales como los de Noruega, nos permiten identificar diferentes aspectos relacionados con la mediación, la reconciliación y los entramados interculturales respecto a la importancia de la música en procesos de reconciliación y trabajo cooperativo. El reconocido investigador de conflictos mediante la música Kjell Skyllstad (1997), de la Universidad de Oslo, realiza el recuento de su experiencia respecto a la introducción de músicas étnicas en contextos multiculturales, a lo cual él llama una "comunidad resonante":

En 1989 la agencia Noruega de Conciertos (NorConcert) inició un programa de tres altos para introducir la enseñanza multicultural de la música en las escuelas primarias noruegas. Ochenta escuelas de la capital y sus alrededores participaron en un proyecto de investigación para determinar qué efectos producían en los alumnos de cuarto grado los músicos inmigrantes cuando introducían la música de sus países de origen. Se hallaron resultados asombrosos, especialmente con respecto a la disminución del hostigamiento y las tensiones étnicas. La música multicultural ahora existe de manera permanente en la agenda de conciertos escolares. Un total de 3.000 conciertos de este tipo han sido presentados a una audiencia de más de un cuarto del total de la población escolar en Noruega (1997: 80). 
Sus perspectivas de trabajo abarcan la reconciliación de fuerzas opuestas, la restauración del equilibrio, aspectos derivados de la músico-dramaturgia con un sustento antropológico, y aspectos como los derechos culturales (Weintraub y Yung, 2009), también son reconocidos en este tipo de procesos que, como sabemos, recuperan el tejido social afectado cuando la guerra o la violencia afectan lo inmaterial. En procesos de resolución de conflictos, Ho-Won Jeong esboza la dinámica estructural del proceso de resolución de conflictos a partir de varios ejemplos internacionales:

\begin{abstract}
De hecho, los cambios del sistema pueden deberse a una búsqueda de nuevas relaciones entre las partes en conflicto. La transición a un sistema de paz implica varios pasos para prepararse para los cambios pequeños o grandes (tales como la eliminación de los prejuicios, la reforma educativa, por ejemplo, en Bosnia Herzegovina, así como un nuevo sistema electoral). En un conflicto asimétrico, los sistemas de transformación pueden afectar a proyectos persistentes y la visión (por ejemplo, la independencia de Timor Oriental (República Democrática deTimor) y la transición a la democracia en Liberia después de las guerras civiles. Relaciones de interdependencia pueden ser creadas por la búsqueda de los valores compartidos y los acuerdos económicos mutuamente beneficiosos (Jeong, 2010: 106).
\end{abstract}

Lo anterior nos dice que si bien en un proceso de resolución conflictual (el cual debe incluir las fases de negociación, mediación, facilitación y reconciliación) habrán cambios, estos pueden ser mínimos o profundos, y se debe identificar si son a corto o a largo plazo. Jeong (2010) puntualiza sobre la necesidad de crear relaciones interdependientes con el fin de puntualizar sobre valores compartidos y beneficios económicos mutuos. Su propuesta enfatiza en la necesidad de reconocer que un proceso de reconciliación o diálogo no puede ser atomizado, ya que por lo general sus propuestas se pueden comprender como soluciones superficiales para problemas profundos del pasado. En este sentido, más allá de enfatizar en la satisfacción de puntos de vista individuales, se debe garantizar una reestructuración que corresponda a las raíces de la injusticia atribuida a las instituciones sociales (Jeong, 2010: 106).

\title{
Asertividad y empatía dentro de la imaginación narrativa
}

La imaginación narrativa (Nussbaum, 2010: 132) y su pensamiento (Bruner, 2010) son necesarios dentro de los esquemas estético-creativos de figuración de salidas no violentas a conflictos tan profundos como los de la guerra de nuestro país. La cooperación intergrupal que pueden encerrar las formas de producción artística y musical en un nivel sociocultural, se pueden nutrir del pensamiento narrativo en marco del diálogo asertivo. Por ejemplo, cuando la música en escenarios de conflicto es usada para otras actividades, como campañas de salud, eventos deportivos, celebraciones y aspectos 
derivados del conocimiento cultural. En todos estos casos la imaginación narrativa y la generación de empatía se conectan de manera directa con estos modos de trabajo, además de aumentar capacidades de transformación evidenciadas en la experiencia y la creación de emociones. Encontramos que este tipo de pensamiento cooperativo y contacto intergrupal remite a formas donde podemos elaborar aptitudes como la empatía (aspecto emocional) y la asertividad (aspecto cognitivo) en los seres humanos.

La primera sitúa las formas como podemos conocer las situaciones de los demás con el fin de ser capaces de comprender en profundidad sus sentimientos, lo cual implica una actitud de alteridad personificada. La segunda hace referencia a la capacidad que tienen las personas de expresar sus ideas en un plano dialógico sin hacer daño a quienes las rodean, es decir, sin someterse pasivamente a sufrir perjuicios, pero tampoco a pasar por encima de sus interlocutores mediante distintas formas de violencia (Chaux, 2012). Estos aspectos conllevan a que los grupos en situaciones de conflicto y post-conflicto asuman posiciones en las negociaciones y diálogos, lo cual además de ser actitudes relacionales puede convertirse en aptitudes psicosociales, debido a que el manejo y resolución consciente de aspectos conflictuales permiten controlar situaciones difíciles, como las que tenemos que vivir a diario, entre ellas el conflicto armado y sus secuelas. Como se aprecia, es posible que las posiciones de nuestra propia regulación vital - que incluyen a los demás - creen una práctica reflexiva, la cual contiene el manejo adecuado de nuestras emociones y la resolución de problemáticas culturales mediante el lenguaje vinculando la música en tanto generador y transmisor de emociones, lo cual complementa nuestro pensamiento intencional imaginativo-narrativo oral y musical.

Una interesante investigación adelantada en la ciudad de Bogotá permitió conocer los procesos creativos musicales de determinadas víctimas del conflicto colombiano (Pinto, 2014). Se originó en el estudio de 33 canciones escritas por un grupo seleccionado de víctimas-compositores. Entre diversos ritmos como el rap, el vallenato y la música del pacífico se pudo comprobar que si bien las personas pueden expresar diversos aspectos de su vida, las líricas arrojaron diversos aspectos derivados de la experiencia del desplazamiento forzado y la guerra. Entre sus hallazgos, se perciben los rasgos de la memoria histórica del conflicto colombiano descritos en las canciones de la mano de sentimientos y expresividades de sus compositores. Por otra parte, se evidenció que existen aún alusiones a la venganza, el refuerzo de estereotipos y algunos distanciamientos entre los actores del conflicto. Aunque la audiencia, en su mayoría ex-combatientes, sintió empatía, reconoció su valor y comprendió su posición.

Otro tipo de estudios sobre factores relacionados con la cultura musical en la vida, como el caso de la salsa 'dura' en Cali analizado por Luján (2012), partió de considerar de modo sociológico la escucha, la colección de discos y la creación de asociaciones de melómanos, al plantear otras maneras de entablar posibilidades de dialogo bajo formas particularmente creativas según el gusto musical. De esta manera la apreciación musi- 
cal, el consumo cultural y las prácticas asociativas generan cohesión social a partir de propósitos comunes como la memorización que subyace al coleccionismo discográfico, tal como plantea esta investigación desde la sociología de la música.

\section{Algunas propuestas de mediación entre la música y la cooperación}

Antes de analizar algunos ejemplos internacionales de posibilidades de intervención a poblaciones en conflicto y posconflicto a través de la música, quisiéramos presentar algunas características adelantadas sobre la música en Colombia, a propósito del Plan Nacional de la Música para la Convivencia (PNMC), debido al posicionamiento que esta política encuentra sobre la necesidad de lo musical en el contexto de la articulación de la creación, la memoria, el diálogo cultural y la participación en el marco del Plan Nacional de Desarrollo 2002- 2006 y el Plan Nacional de Cultura 2001-2010 ${ }^{10}$. La articulación de este programa trata de abordar las problemáticas que emanan de la dificultad de la promoción cultural y educativa en Colombia, según la especificidad de la música y las necesidades de desarrollo de sus diversos componentes poblacionales (formación, dotación de instrumentos y materiales musicales, información e investigación, creación, emprendimiento, circulación y gestión). Como el mismo Ministerio de Cultura reconoce en su balance, las falencias de lo musical nivel nacional son enormes:

- Procesos educativos débiles.

- Pocos especialistas e instituciones dedicadas a la investigación musical.

- Precarias condiciones laborales y socioeconómicas de los músicos.

- Escasas formas organizativas como asociaciones, fundaciones, sindicatos, por mencionar algunas.

- Insuficientes procesos de intercambio nacional.

- Escasa edición y divulgación del patrimonio musical colombiano (Departamento Nacional de Planeación, s.f.).

La práctica musical y las dificultades que vive la expresividad sonora en la actualidad sobrepasan lo anteriormente señalado. Por ejemplo, el desconocimiento de las músicas nacionales, la ausencia tecnológica respecto a lo que implican los procesos de producción musical, los prejuicios que sufren algunas músicas regionales, rurales o urbanas respecto a un posicionamiento en el desarrollo musical contemporáneo, las cooptaciones por 
parte de las industrias culturales, el engrisamiento de la homogeneidad por parte de la monocultura que propone el imperativo capitalista (por ejemplo, el fenómeno de la world music), entre muchos otros factores que comprometen la musicalidad heterogénea en esta parte del planeta. Sin ninguna duda esta política podría diseñar mecanismos de comunicación interculturales a partir de las propias comunidades con miras a un posconflicto, donde la necesidad de espacios de articulación, dialogo y reflexión son indispensables. Algunas críticas sobre esta política apuntan a los retos que ella enfrenta en la formación y el reconocimiento de la educación musical. Para Rivas (2011) quien hace un recuento sobre el PNMC: "La actividad musical en los diferentes municipios está orientada en su mayoría a la programación de eventos y a la proliferación de escenarios" (Rivas, 2011: 47). Esta perspectiva pedagógica hace hincapié en la pertinencia de abordar lo musical más allá de aspectos netamente materiales, a propósito de fundamentar en los espacios convivenciales municipales una conciencia a nivel colectivo sobre la trascendencia de la tolerancia, la paz, lo tradicional y lo popular.

Las prevenciones que un espacio socioestético de participación debe asumir son muchas. En el caso de la música, la falta de una experticia en la promoción cultural puede incurrir en la difusión de aspectos espectaculares, que si bien proporcionan 'divertimento' desconocen las realidades que se ocultan en la perversidad de la demagogia y el populismo regional/nacional que utiliza lo musical, lo dancístico y la excusa de la cultura como mediación ideológica con fines electorales. La centralidad de la música -en una sociedad democrática - en términos de participación e inclusión, viabiliza una potencialización de los aspectos biopsicosociales de los miembros de cualquier comunidad. Los aspectos psicosociales a la luz de la práctica musical puntualizan los mecanismos insospechados que las actividades artísticas generan.

\section{Musicoterapia en contextos de guerra}

La música también es utilizada para generar salud y responder a diversas necesidades de calidad de vida, en la generación de bienestar a través de las experiencias musicales. Esta salud biopsicosocial adecua el trabajo de problemáticas como la depresión, la ansiedad, la melancolía y otras patologías ligadas a trastornos psicoafectivos, a partir de los efectos biológicos de la música. Las relaciones que establecen las ciencias cognitivas y algunos desarrollos artísticos actuales establecen canales de comunicación donde lo musical ejerce un papel fundamental respecto a las emociones, la cognición, la fisiología y sus respuestas motrices en función del sujeto. Como veremos a continuación en muchas ocasiones son experiencias significativas.

En la actualidad el campo emergente de la musicoterapia en contextos de guerra y resolución de conflictos es enorme. En este campo la música cobra un proceso vital y propone trabajar con menores; por ejemplo, el estudio realizado con una comunidad 
de niños bajo el trauma de la guerra en Bosnia-Herzegovina. El trabajo de Lang et al. (2002) abordó las temáticas relacionadas con secuelas y cicatrices del conflicto con el fin de adelantar esfuerzos para resarcir el daño de la violencia y promover estados emocionales pre-guerra. El estudio profundizó en aspectos terapéuticos derivados de las secuelas y los efectos psicosociales de la violencia, producto de la guerra, las torturas, y las diferentes experiencias de la inmigración. Su perspectiva fue de apoyo, bajo procesos musicoterapéuticos de supervisión y terapias personales a pacientes que vivieron eventos potencialmente mortales y experiencias traumáticas, utilizando técnicas como la iniciación y los cambios necesarios en la supervisión, la delimitación de los temas centrales relacionados al trabajo clínico, el trabajo de traductor (del idioma) y el mantenimiento de la supervisión a distancia mediante llamadas en la relación paciente-terapista. Este ejercicio experimentó el cambio a nivel clínico de la perspectiva terapéutica convencional, y demostró que es posible realizar un trabajo músico terapéutico en un proceso largo con una posterior fase a distancia, con todo lo que esto implica.

Otras investigaciones en este campo versan sobre los traumas de la guerra y los esfuerzos de músicoterapistas para librar a las víctimas infantiles del conflicto, tal como es el caso en Singapur ( $\mathrm{Ng}, 2005)$, y con grupos de investigación participativa creados a partir de la experiencia de jóvenes refugiados en comunidades escolares (Hunt, 2005) con el fin de evidenciar las relaciones entre las transformaciones del conflicto a partir de la musicoterapia (Bergh y Sloboda, 2010). Para Ng (2005) fue vital la recolección de información sobre los efectos de la guerra a través de entrevistas, puntualizando sobre las crisis vividas por sobrevivientes al terrorismo y sus formas relacionadas de violencia. La creación de grupos de trabajo en la modalidad de tratamiento fue útil, sobre todo en la promoción de la paz en Singapur y la posibilidad de reconocer los regímenes ideológicos y las consecuencias a las que las víctimas fueron sometidas en los casos donde hubo participaciones directas o indirectas en grupos ultraviolentos. Hunt (2005) partió de la creación de un método de trabajo conocido como Action Research, el cual se centra en el conocimiento colectivo, a partir de algunas ideas de Kurt Lewin, Karl Marx y Paulo Freire. La relación terapéutica con jóvenes refugiados comprendió el entorno y la música en sí misma, a partir de la bibliografía con la que el investigador articuló técnicas como la improvisación, el canto, la música, el movimiento y la escritura de canciones usando el hip hop y el rap. El marco operativo de esta apuesta se basó en la orientación de Lewin adoptada el autor, la cual plantea la definición del objeto y la identificación del problema, la investigación de los hechos y la realización de un plan general, acciones que permitieron la recolección de datos y la evaluación-análisis de los mismos. Para Hunt (2005) la influencia de experiencias traumáticas como irse de los hogares, los estigmas sociales, la soledad, el rechazo y el racismo que se viven en la sociedad son susceptibles de abordarse en un contexto escolar, afrontando la problemática de ser joven y refugiado. 
En países azotados por la violencia como Kenia, con cerca de 500.000 refugiados (20.0oo de ellos niños) para el año 2001, también se reportan contribuciones desde la musicoterapia (Akombo, 2001). Otras investigaciones abordan el trabajo con refugiados veteranos de guerra y víctimas de abuso sexual a través de la música al identificar diferentes métodos de trabajo y puntualizar sobre las particularidades de cada trauma (Orth, 2005). En su práctica, Kennedy (2001) trabajó con sobrevivientes de torturas cometidas en la Guerra de Bosnia en Sarajevo, utilizando el reiki para realizar terapias complementarias a nivel músicoterapeútico. Su experiencia se desarrolló en un centro para sobrevivientes a la tortura, y propuso la música raiki - en tanto acto-como fuente de diversos logros en múltiples niveles de concentración. Las técnicas aplicadas fueron la reflexología, la aromaterapia y la escucha-práctica del raiki, ya que es una música meditativa y de relajación, al lado de diversos tratamientos médicos formales. Los resultados fueron positivos como parte de un proceso de experimentación basado en las vibraciones positivas y la esperanza de una nueva vida.

En este tipo de trabajo existe un cúmulo de factores que se cruzan respecto a la debida atención del trauma post-guerra. Primero se puntualiza en las relaciones socioculturales de los entornos de guerra y de igual manera en las posibilidades que cada contexto brinda. Segundo, se hace hincapié en las historias de vida y se personalizan las particularidades de cada personalidad y sus características familiares, sociales, participativas y de roles asumidos. Esto conlleva identificar los síntomas y reducir el stress emocional producto de tales experiencias, lo cual es identificado como etapa postraumática del proceso. De esta manera, se establecen medios para identificar las elecciones existenciales que las personas deben asumir para su vida, con el fin de facilitar su integración a sus sociedades (Orth, 2005).

Cuando incluimos aspectos de la musicoterapia como campo de investigación y trabajo dentro de sociedades en conflicto y post-conflicto, quisimos plantear que la música en contextos altamente violentos también puede tener aspectos medicinales prácticos en tanto ciencia de la salud. Esto nos indica que la música posee diferentes niveles de trabajo, especialmente cooperativo. Sabemos que existe un 'continuum de paz y guerra', y como reconoce O'Connell: "las primeras reacciones pacíficas examinan las intenciones bélicas, las segundas miran los papeles paradójicos de la música en los conflictos y su transformación" (2011: 124). La transformación conflictual debe ser un objetivo, aunque parezca obvio: en un proceso de esta magnitud las secuelas de la guerra pueden imponerse al sentido pacificador del diálogo concertado.

$\mathrm{Al}$ hacer un balance sobre la musicoterapia en contextos de guerra resulta difícil subvalorar la importancia de esta práctica como posibilidad de trabajo en un marco operativo de aplicación a las problemáticas emanadas de las secuelas de las diferentes violencias. En el posconflicto colombiano este campo contribuiría de manera puntual a generar espacios de reconocimiento sobre las complejas dinámicas que articulan las 
condiciones socioculturales y las desigualdades que desencadenan el accionar de la maquinaria violenta.

\section{Conclusiones parciales: ¡Hacia una paz armonizada!}

Este artículo reflexionó sobre las posibilidades que la música puede aportar a la resolución y transformación de conflictos (por ejemplo, desde las propuestas de Cascón, s.f., y de Jeong, 2010), en sociedades en post-conflicto, post-guerra y transiciones sociales. Para ello se articularon algunas posiciones teóricas desde la música y los aspectos conflictuales de su elaboración desde un plano intercultural. Así como el papel que juega la música en una sociedad en transición donde el diálogo debe ser la fuente primordial de comunicación. Además, se articularon diversas perspectivas teóricas y de trabajo práctico en que la música fue central respecto a la resolución de conflictos de diversa índole. Para esto se presentaron diversos casos donde la música y su relación con la guerra estuvieron vinculadas mediante posibles alternativas de avance, como las investigaciones etnomusicológicas y la musicoterapia, en la práctica profesional con sujetos-víctimas que vivieron conflictos bélicos.

Creemos que con esta serie de argumentaciones y demostraciones queda claro que el potencial de la música en la promoción de la paz y escenarios de no-guerra es decisivo, a partir de los casos expuestos en el plano internacional, fruto de la producción científica y académica sobre el tema. En nuestra investigación vimos cómo en el estudio de un caso musical étnico en su relación con la música en un contexto (por ejemplo urbano), factores como la violencia y los conflictos sociales de esas realidades (segregaciones, discriminaciones, destierros, exterminios) daban un matiz interesante en el plano etnomusicológico para la comprensión de esas problemáticas (Luján, 2016b). Escenarios donde las juventudes y sus culturas entre ellas el hip-hop (Pinto, 2014; Luján, 2016a, 2016b), permiten responder a los interrogantes que plantean las maneras de incluir la cuota de pacificación a sectores poblacionales donde la secuelas de la guerra, la segregación y la violencia sistemática (por ejemplo a jóvenes afro o indígenas) son urgentes si lo que se piensa en la sociedad en general son las formas de mediación entre los conflictos y su resolución.

El reconocimiento de prácticas musicales locales ayuda a la compresión de los modos a través de los cuales las comunidades ilustran sus situaciones mediante sonidos, aunque en algunos casos se presenten diferentes usos internos de lo musical. En los aspectos musicológicos (sistemas de ejecución instrumental, organología, registros acústicos), en el campo ideológico (discursos, relaciones políticas, capacidad de movilización, ética, valores), a través de los componentes estéticos (tendencias, escenas, estilos, símbolos), en los aspectos religiosos (identificaciones espirituales, usos rituales, cosmologías, ico- 
nologías, trascendencias), sobre el bienestar biopsicológico (procesamientos cognitivos, bienestar en la calidad de vida, tratamiento clínico, estados anímicos) y en los aspectos socioculturales (ideas, ancestralidad, actividades grupales, patrones de comportamiento, clase, organización, condiciones y condicionamientos sociales, convivencia, interacciones, apropiaciones del territorio, rutinas, apropiaciones, identificaciones), la música permite la indagación de una mezcla de diversos campos de análisis, si así se quiere. Brumann (1999: 13) escribe a propósito de la noción de cultura: "Cualquier concepto científico es simplemente un constructo y tiene sus costos, pero una vez que se han encontrado sus ventajas para contrapesar estos costos debería poder ser empleado con una conciencia clara". ${ }^{11}$

Considero que la situación que vive Colombia actualmente, en relación al escenario del posconflicto, debe permitir la inclusión de mecanismos culturales en la resolución del complejo conflicto nacional en sus diferentes niveles. Como pudimos ver, el diálogo y la transformación conflictual a través de la práctica y la reflexión musical son ejemplos inspiradores de otras maneras creativas de entablar comunicación articulando el respeto mutuo como pilar del reconocimiento no tanto de las diferencias, sino mejor de la igualdad. Si es que consideramos que la guerra se basa precisamente en eso: en enaltecer las diferencias.

\section{Referencias}

AKOMBO, D. O. (2001). Reporting on Music Therapy in Kenya. Voices: A World Forum for Music Therapy, 1 (1). https://voices.no/index.php/voices/article/view/45/29 Consultado: 13/12/2015.

ARAÚJO, S. \& MIEMBROS DEL GRUPO MUSICULTURA. (2006). Conflict and Violence as Theoretical Tools in Present-Day Ethnomusicology: Notes on a Dialogic Ethnography of Sound Practices in Rio de Janeiro. Ethnomusicology, 50 (2): 287-313.

ARIAS, M. A., CAMACHO, A., IBÁÑEZ, A. M., MEJÍA \& D., RODRÍGUEZ, C. (2014). Costos económicos y sociales del conflicto en Colombia: ¿cómo construir un posconflicto sostenible? Notas de Política, (17). https://egob.uniandes.edu.co/images/books/pdf/nota17.pdf Consultado 13/03/2015.

BERGH, A. (2008). Everlasting Love: The Sustainability of Top-down vs Bottom-up Approaches to Music and Conflict Transformation. En Kagan, S. y Kirchberg's, V. (Eds) Sustainability: A new frontier for the arts and cultures (pp. 351-382) Germany: VAS-Verlag.

BERGH, A. \& SLOBODA, J. (2010). Music and Art in Conflict Transformation: A Review. Music and Arts in Action, 2 (2). http://musicandartsinaction.net/index.php/maia/article/view/conflicttransformation consultado $13 / 12 / 2015$.

11. Traducción propia. 
BRUMANN, C. (1999). Writing for Culture: Why a Successful Concept Should Not Be Discarded. Current Anthropology, 40: 1-27.

BRUNER, J. (2010). Realidad mental y mundos posibles. Barcelona, España: Gedisa.

CAMACHO, A. \& RODRÍGUEZ, C. (2013). Firm Exit and Armed Conflict in Colombia. Journal of Conflict Resolution, Peace Science Society (International), 57 (1), 89-116.

CARVALHO, J. J. (2004). Las culturas afroamericanas en Iberoamérica: lo negociable y lo innegociable. En UNESCO. (2004). Los Afroandinos de los siglos XVI al XX. (pp. 177- 206) San Borja, Perú: UNESCO.

CASCÓN, P. (s.f.). Educar en y para el conflicto. Barcelona, España: Universidad Autónoma de Barcelona.

CHAUX, E. (2012). Educación, convivencia y agresión escolar. Bogotá, Colombia: Uniandes-Taurus.

DEPARTAMENTO NACIONAL DE PLANEACIÓN. (s.f.). Plan nacional de música para la convivencia. Recuperado de https://spi.dnp.gov.co/App_Themes/SeguimientoProyectos/ResumenEjecutivo/1190001280ooo.pdf Consultado 1/06/2016.

GIOVANNETTI, J. L. (2001). Sonidos de condena. Sociabilidad, historia y política en la música reggae de Jamaica. México D.F., México: Siglo XXI.

GÓMEZ, R. (2011). Reseñade John Morgan O'Connell y Salwa El-Shawan Castelo-Branco (Eds.) Music and Conflict. TRANS Revista. Transcultural de Música/Transcultural Music Review 15, http://www. sibetrans.com/trans/publicacion/16/trans-15-2011 Consultado 20/12/ 2012.

HARBOM, L. \& WALLENSTEEN, P. (2007). Armed Conflict, 1989-2006. Journal of Peace Research, $44(5): 623-34$.

HASKELL, E. (2015). The Role of Applied Ethnomusicology in Post-Conflict and Post-Catastrophe Communities. En Pettan, S. y Titon, J. T. (Eds.) The Oxford Handbook of Applied Ethnomusicology (pp. 453-480) New York, USA: Oxford University Press.

HUNT, M. (2005). Action Research and Music Therapy: Group Music Therapy with Young Refugees in a School Community. Voices: A World Forum for Music Therapy, 5 (2). https://voices.no/index.php/ voices/article/view/223/167 consultado 13/12/2015.

JEONG, H. W. (2010). Conflict management and resolution: an introduction. New York, Abingdon, USA, England: Routledge.

KENNEDY, P. (2001). Working with Survivors of Torture in Sarajevo with Reiki. Complementary Therapies in Nursing o Midwifery, 7, 4-7.

KURKELA, V. (1995). Local Music-Making in Post-Communist Europe: Mediatization and Deregulation. East European Meetings in Ethnomusicology, 2, 105-115. 
LANG, L., MCINERNEY, U., MONAGHAN, R. \& SUTTON, J. P. (20O2). Processes in Listening Together - an Experience of Distance Supervision of Work with Traumatised Children. En Sutton, J. P. (Ed.) Music, Music Therapy and Trauma: International Perspectives (pp. 211-230) London, England: Jessica Kingsley.

LIEBMANN, M. (1996). Arts Approaches to Conflict. London and New York: Jessica Kingsley Publishers.

LUJÁN, J. D. (2016a). Formas de Producción Sociocultural de la Población Afrojuvenil en la Ciudad de Cali: El caso del rap caleño en la década del noventa. (Tesis de maestría), Universidad Distrital Francisco José de Caldas, Maestría en Investigación Social Interdisciplinaria, Bogotá.

LUJÁN, J. D. (2016b). Los hijos de la violencia y la segregación: La escena afrojuvenil del rap en la ciudad de Cali en la década de los noventa. Methaodos.revista de ciencias sociales, 4 (1): 177-188. http://dx.doi.org/10.17502/m.rcs.v4i1.111

LUJÁN, R. C. (2012). Las audiciones de salsa en Cali. Caracterizaciones sociológicas. Cali: Luján Editores.

NG, W. F. (2005). Music Therapy, War Trauma, and Peace: A Singaporean Perspective. Voices: A World Forum for Music Therapy, 5 (3). https://voices.no/index.php/voices/article/view/231/175 Consultado: 13/12/2015.

NUSSBAUM, M. C. (2010). Sin fines de lucro. Porqué la democracia necesita de las humanidades. Buenos Aires, Argentina: Katz.

O'CONNELL, J. M. (2010). Introduction: An Ethnomusicological Approach to Music and Conflict. En O'Connell, J. M. y Castelo-Branco, S. E. (Eds.) Music and Conflict (pp. 1-14) Urbana, Chicago y Springfield, USA: University of Illinois Press.

O'CONNELL, J. M. (2011). Music in War, Music for Peace: A Review Article. Ethnomusicology, 55 (1), $112-127$.

O'CONNELL, J. M. \& CASTELO-BRANCO, S. E. (Eds.) (2010). Music and Conflict. Urbana, Chicago y Springfield, USA: University of Illinois Press.

ORTH, J. (2005). Music Therapy with Traumatized Refugees in a Clinical Setting. Voices: A World Forum for Music Therapy 5, (2). https://voices.no/index.php/voices/article/view/227/171\#note1 Consultado: 13/12/2015.

PETTAN, S. (1998). Music, Politics, and War: Views From Croatia. Zagreb, Croacia: Institute of Ethnology and Folklore Research.

PIESLAK, J. R. (2009). Sound Targets: American Soldiers and Music in the Iraq War. Bloomington, USA: Indiana University Press.

PIKETTY, T. (2014). El capital en el siglo XXI. México, D. F.: Fondo de Cultura Económica. Primera edición electrónica. 
PINTO, M. E. (2014). Music and Reconciliation in Colombia: Opportunities and Limitations of Songs Composed by Victims. Music and Arts in Action, 4 (2). http://www.musicandartsinaction.net/index. $\mathrm{php} / \mathrm{maia} /$ article/view/musicreconciliationcolombia/97 Consultado 13/12/2015.

REYES, A. (1999). Songs of the Caged, Songs of the Free: Music and the Vietnamese Refugee Experience. Philadelphia, USA: Temple University Press.

REYES, A. (2006). Music in Conflict: Ethnomusicological Perspectives. Champaign, USA: University of Illinois Press.

RITTER, J. \& DAUGHTRY, J. (Eds.) (2007). Music in the Post-9/11 World. New York y London, USAEngland: Routledge.

RIVAS CAICEDO, L. D. (2011). La etnomusicología en los planes de estudio de formación del licenciado en educación musical de la Licenciatura en música de la Universidad de Nariño en Colombia. (Tesis doctoral en Pedagogía). Facultad de Filosofía y Letras, Universidad Nacional Autónoma de México, México D.C.

ROBERTSON, C. (2010). Music and Conflict Transformation in Bosnia: Constructing and Reconstructing the Normal. Music and Arts in Action, 2 (2). http://musicandartsinaction.net/index.php/ maia/article/view/conflicttransformationbosnia consultado 13/12/2015.

SACKS, O. (2007). Musicophilia: Tales of Music and the Brain. New York, USA: Alfred A. Knopf.

SEEGER, A. (1987). Why Suyá Sing. Cambridge, USA: Cambridge University Press.

SEEGER, A. (2010). The Suya and the White Man: Forty-five Years of Musical Diplomacy in Brazil. En O'Connell, J. M. y Castelo-Branco, S. E. (Eds.) Music and Conflict (pp. 109-125) Urbana, Chicago y Springfield, USA: University of Illinois Press.

SEMANA. (2013, diciembre 11). 10 años del Plan Nacional de Música para la Convivencia. Cultura. Recuperado de http://www.semana.com/cultura/articulo/concierto-para-celebrar-10-anos-del-plan-nacional-de-musica-para-la-convivencia/367915-3 Consultado 1/o6/2016.

SKYLLSTAD, K. (1997). Music in Conflict Management-A Multicultural Approach. International Journal of Music Education, 29: 73-80.

SOCIETY FOR ETHNOMUSICOLOGY. (2007, febrero 2). SEM Torture. Position Statement on Torture. http://www.ethnomusicology.org/?PS_Torture consultado 14/O2/2015.

STIGLITZ, J. (2012). El precio de la desigualdad. Madrid, España: Taurus.

SUGARMAN, J. C. (1999). Imagining the Homeland: Poetry, Songs, and the Discourses of Albanian Nationalism. Ethnomusicology, 43 (3), 419-458.

SUGARMAN, J. C. (2010). Kosova Calls for Peace: Song, Myth and War in an Age of Global Media. En O'connell, J. M. y Castelo-Branco, S. E. (Eds.) Music and Conflict (pp. 17-45) Urbana, Chicago y Springfield, USA: University of Illinois Press. 
URBAIN, O. (Ed.) (2008). Music and Conflict Transformation: Harmonies and Dissonances in Geopolitics. London, England: I.B Tauris in association with the Toda Institute for Global Peace and Policy Research.

WARREN, J. R. (2014). Music and Ethical Responsibility. Cambridge, United Kingdom: Cambridge University Press.

WEINTRAUB, A. y YUNG, B. (2009). Music and Cultural Rights. Chicago-Urbana, USA: University of Illinois Press.

ZELIZER, C. M. (2003). The Role of Artistic Processes in Peacebuilding in Bosnia- Herzegovina. Peace and Conflict Studies, 10 (2), 62-75.

ŽIŽEK, S. (2006). Órganos sin cuerpo. Sobre Deleuze y sus consecuencias. Valencia, España: Pre Textos. 